\title{
Regional Integration in Asia: Prospects and Challenges
}

\author{
Sa Zeng \\ School of Foreign Languages, Shenzhen University \\ Shenzhen 518060, China \\ Tel: 86-755-2673-2890_E-mail: zengsa@szu.edu.cn
}

\begin{abstract}
Think locally, acting globally. With this motto in mind, this paper aims to show how the becoming ASEAN and its powerful neighbors could avoid costly errors in forming a working union of nations by not looking at the completed total rather than a first, tangible step. By looking at the European Union and how it became what it is today, Asia will be able to avoid exaggerated expectations towards the speed at which a solid agreement can be reached. Especially in regards to the psychological mindset of decision makers grown up in nation centered rather than globally oriented societies will Europe be able to provide a lesson. The paper concludes that a working economic union should be the first step on the way to a united Asia. The underlying condition that most of Asia's economies are controlled by Chinese emigrants provides for a notion which shall be explored as a possible stepping stone on the way to a working economic integration.
\end{abstract}

Keywords: Regionalism, Agenda 21, ASEM, Asian Union, Asian Development, ASEAN, EU, Asia, Europe

\section{Introduction}

Having monitored the emerging of the European Union EU over the past few years, there are no doubts that there are many challenges to extended regionalization, such as unemployment, high taxation and lopsided regional development. However, in watching the economic growth of EU members and the emergence of the Euro and its relative strength to the U.S. dollar, it is apparent that the prospects of prosperity and a brighter economic future far outweigh the challenges. The success of the EU should cause members of ASEAN (Association of South East Asian Nations) to work closely together to further develop and strengthen their economic and cultural ties, for the benefit of all members.

\section{History and Current Situation}

In East Asia, the process of regionalization has been driven by market forces or state-sponsored regional projects. ASEAN was established in 1967 and initially there were 5 members: the Republic of Indonesia, Malaysia, the Republic of the Philippines, the Kingdom of Thailand and the Republic of Singapore. With ASEAN's expansive influence, 5 more countries joined the group and made it a bigger family. They are the Socialist Republic of Viet Nam, the Lao People's Democratic Republic, the Union of Myanmar, Brunei Darussalam and the Kingdom of Cambodia. Until 1998, ASEAN became a regional cooperative union with ten Asian countries, 4.5 million square kilometer territory, 500 million population and 700 billion US dollars of GNP. ASEAN has made up its own kingdom which is similar to the European Union (EU) in Europe.

Obviously, ASEAN is different from EU in many aspects. After all they are located on different continents. However, there are still some similarities between ASEAN and EU. Firstly, the member countries of each have similar religious history. Most Europeans believe in Christianity while the religious root in Asia is Taoism. Both of them overcame persecution from other religions before they became the principle regional religions. This is really important. "Collective identification merges the self and the other into a single identity and involves shared characteristics.... Collective identity, in short, is a distinct combination of role and type identities, one with the casual power to induce actors to define the welfare of the other as part of that of the self, to be altruistic. The effect of people perceiving themselves of part of a group leads to group optimizing behavior. The most important work in this regard is offered by John Nash and his famous Nash equilibrium: The best decision optimizes the welfare of the individual and, at the same time, that of the group members if his or her group. (Nash, 1950/51). In other words, altruistic actors may still be rational, but the basis on which they calculate their interests is the group or team". That's what regionalization needs. Additionally, both Europe and Asia have undergone the distress of wars. Their leaders and people made a leap in the war, understanding that only by relying on collective strength can the possibility of the third world war and negative 
effects of economic globalization be resisted. One could understand the building of a regional alliance as the formation of an interest group. The avoidance of war and the maintenance of peace as well as supporting economic prosperity are two reasons which could well form the underlying. One does not go without the other.

\section{Challenges}

As was the case for the EU, it seems that Asia can build up an economic group which involves most of the Asian countries, similar to what was done in the EU. One should not that the emphasis in ASEAN lies on "economic cooperation" much rather than a political union.

Looking at the EU will highlight some areas which are and were problematic in Europe and, could be so in Asia as well. Before the European Union was even ready to be getting close to what it is today, two world-wars were necessary. Only after the Second World War did France and Germany commence the first small economic collaboration in 1952 (Coal and Steel Union) which later laid the foundation for a greater economic union (1958, Nuclear and Economic Union). The careful foundation of the "EU" did not happen until 1992 and the first solid integration of all coexisting treaties has not happened until today. And why not? Ireland as the last remaining member refused to ratify the otherwise completed EU contract.

In all cross-cultural groups, functioning depends on recognition- and respect- of all member' individual background as well as the avoidance of any culture's dominance of the others (Adler 2001). Trusting one another is a time consuming activity, possibly that's why the EU is not yet "complete".

Regarding the birth pains in Europe it is worthwhile considering the Asian Development Bank's (ADB) strategy paper. In "Strategy 2020" the ADB identifies a total of nine challenges, the top three being: Poverty, income gap between people and demographic challenges (ADB 2008).

Again looking to the European Union, strong gradients in economic prosperity have been a constant headache in developing joint policies. Also it should also be mentioned, that the discussion about a "core EU" consisting of only the economically strongest partners is a seasonally recurring event. Considering the above mentioned challenges identified by the ADB, the evolving ASEAN should be prepared for similar discussions as the economic gradient in Asia is at least as strong as that in the EU.

\section{Trends and Prospects}

ASEAN is growing. Japan has signed the Free Trade Agreement with Singapore and is discussing a similar agreement with the ROK. China and the ASEAN have declared that they will set up a free trade zone in 2010 and China is intensifying its efforts to study the feasibility of entering into additional free trade agreements with Japan, and the ROK. Close economic intercourse between East Asian countries is unprecedented and economic dependence between them is on the rise. Interest interrelation is the basis of regional identification, while recognition of shared interests is the key to promoting identification.

Regional integration is a global trend. Areas of the world are tying closely together. The Asian governments have come to realize the necessity of regional integration and the everyday citizen is coming to realize it as well. The Asian financial storm is a classic example. In 1997 the Asian economy was seriously damaged causing chaos in the stock market and the devaluation of many Asian currencies. It hit the governments hard but the average person even harder, spurring East Asian countries to join hands in resisting the negative effects of economic globalization and causing East Asian regional integration to enter a new phase. As a direct result, regionalization in Asia has become a trend which will improve the economic and cultural cooperation.

Considering the prospects: what Asia has that Europe doesn't have is the world's largest labor force. We can change disadvantage into advantage which means to improve productivity through both technology and labor. The good use of labor force can increase people's income and decrease unemployment. In this case, the development of ASEAN members can lift the socio-economic standards of its members by raising the standards of living in their countries. The raising of the living standards in their countries also lifts the socio-economic standards of the whole unit. It is a win-win situation.

The significance of establishing an economic group in Asia is necessary and rational. The success of the EU provides a blueprint to follow and provides significant data which Asia can learn from. Since building up the single market, EU removed 15 trade borders, created 2.5 million positions for people all around the world, and netted 900 billion EU dollars.

\section{The Chinese Diasporas in Asia}

The ASEAN nations comprise a total of about half a billion people, most of them being native to their respective home countries. An extremely interesting notion is that all of the Southeast Asian nations maintain relatively small Chinese minorities, i.e. populations of Chinese emigrants. 
One general fact that sets Chinese populations aside from that with native roots is the propensity for engaging in business transactions. Whether this propensity is born out of necessity or a difference in culture is secondary to this argument. Observations from the US and Malaysia suggest that a strong driver in this behavior is born out of necessity. The Chinese diasporas being mostly recent, at best second or third generation immigrants, lack access to "for granted income", such as government positions and/or jobs obtained through kinship in established businesses. Niche forming and occupation is a natural behavior to minorities whose cultural values set them aside from the majority population. Examples here are, e.g. newspaper stands or laundry businesses, which are exclusively run by one ethnic minority. Since there is no legal protection for such behavior, it can be deduced that these minorities resort to their own system when it comes to protecting themselves in this regard, i.e. organized crime.

What distinguishes Chinese minorities in ASEAN from those elsewhere?

Certain ASEAN nations are called "tigers", for their successful economic development in recent decades. Notably in Malaysia and Thailand, the majority of the population, native Thais and Malays, are an easy-going laid-back people who, e.g. in universities, differentiate themselves from their fellow countrymen of Chinese origin in the way, that they often refuse to frequent a university course which is also frequented by Chinese students. This behavior is, as it might seem, not racists rather than self-protective. Chinese students are pushed hard by their elder generations to study and work hard. Consequently, competition and contribution value in those classes is above average- making it more difficult to obtain a good grade.

This behavior translates into the working population, i.e. two thirds of the Malay GDP of 2002 was generated by Chinese (and Indian) minorities who offer, together app. $20 \%$ of the total population. The situation is similar in the Philippines and Thailand.

The how about a stepping stone for an economic union?

It would be wise for ASEAN (and Chinese) public representatives to bear in mind the economic structure of Asia when building an Asian Union.

Research done in 2002/03 among European manufacturers in ASEAN already suggested that one would make investment decisions majorly based on trade policy decisions of the People's Republic of China. During this period, interviews were conducted with representatives from large European car manufacturers such as BMW and Daimler which had, at this time, just invested in factories in Thailand, assembling completely knocked kits (CKD) of parts produced in Germany. These type of factories were and are used as a step in between a full production line and pure import business and normally, this behavior is looked upon benevolently by respective governments. Although CKDs are, in terms of value, almost completely imported, some value does get added and some knowledge does get transferred, in return for which those companies are e.g. import tax exempted.

The case of ASEAN and China (and Japan and Korea) again shows the need for a union. The more expensive an investment in any single market, the more security this investment will need in terms of serviceable markets. If Asia maintained its sovereign behaviors in regard to tax policies, import and export regulations, individual countries face the risk of either not being serviced and / or not being considered for investment at all.

Simultaneous to large European companies opening Asia serving manufacturing centers in China, Chinese companies began to repatriate their own low-cost production to ASEAN nations, as labor cost in some coastal regions of China is not "low-cost" any longer. Quite often, Chinese administration welcomes or induces such investment by, e.g. removing preferential policies which might have been initial reasons for a company to move to that location.

One of the most famous examples is Shenzhen based TV producer TCL, which was among the first (interview 2004) to move production away from the coast.

The notion to be explored is such that the Asian Union or any free trade area would not be an "equal" partnership between sovereign nations, yet not equal in economic terms. In a partnership between ASEAN and the People's Republic of China, ASEAN provides roughly $25 \%$ of the total population. The degree of organization of ASEAN will never equal that of the PRC and such, ASEAN leaders would be wise to accept that China must be the implicit leader in an Asian Union. Considering China's non-invasive foreign policy and, historically, lack of imperialist behavior makes it an ideal candidate, disregarding the fact that it is the only one.

\section{Recommendations}

As Asia is still developing in most parts, development is a tight rope walk between maintaining stable and sustainable economic growth on the one side and investor's confidence on the other. Only if these two factors are given, will those two factors eventually intersect, then delineating the transition from developing to developed nation. In other words, during the first years of a developing country's development process, foreign contribution to GDP development pulls, in a well managed development, domestic contribution to GDP along until local contribution to GDP is larger than foreign contribution. This development is also called "sustainable development". Several nations, many of these on the African 
continent, have not experienced a well managed development process and have also not experienced the status of being economically and politically stable nations.

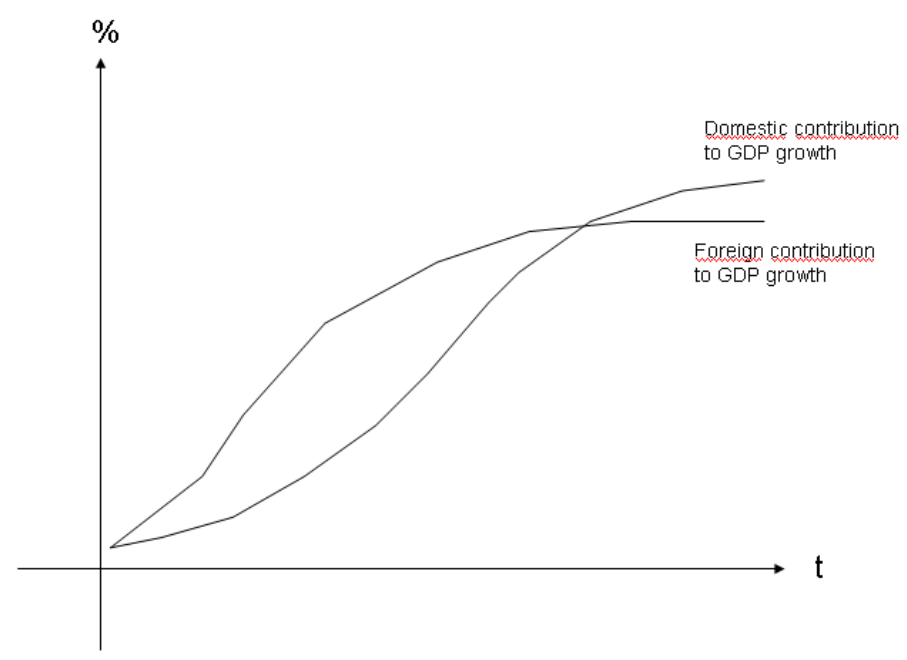

For Asia, the major task will be how to structure the union. Again, Beijing provides a type of policy making, which sets a bright- and undoubtedly successful- example. Instead of relying on US driven (and currently spectacularly failing) free market philosophy, a more mechanist paradigm seems to provide a more efficient outcome on a macroeconomic level.

Instead of letting all industry develop freely, certain areas- provinces or parts of provinces- are market for development by designated industries. These might either be naturally determined, i.e. a region with large amounts of natural resources, will of course receive promotion for related industries, while undetermined regions which might offer "only" space and a sufficient labor force, can be freely determined by the central government.

Example: Shenzhen, with a total population of 14 million which is still increasing, in southern China was marked for high-tech development adopting modules like government-supported high-tech parks with favorable conditions for young entrepreneurs and new start-ups coming from all parts of the country and even the world - an areas in which less than 30000 fishers and farmers dwelled thirty years ago. Today, Shenzhen has had to cut preferential tax treatment and has, as above mentioned TCL, long since begun to transfer low-value added labor intensive industries to China's hinterland and / or to neighboring ASEAN nations such as Vietnam and Cambodia.

Why not apply a similar policy to Asia as a whole? Most ASEAN nations have a lower population than most of China's provinces. In this sense, Asia can also look to Europe and its related problems- i.e. the struggle between economic efficiency and national ego to adjust in the interests of the union. The EU makes it clear, how long and tedious this process is. It also makes clear, how nations who have been fighting each others still in the last century, i.e. France and Germany (comparable to Japan and China) are able to join hands and, most of the time, care about the greater good.

\section{The Sciences}

If social notions such as sustained peace and freedom are not enough, economic theory offers plenty of ammunition for the above outlined argument. John Nash- the Nash Equilibrium- even offers the ultimate reason, such that most efficient outcomes are obtained when thinking egoistically and for the group one is embedded in simultaneously. Eric Maskin (together with Leonid Hurcwicz and Myerson (CHECK)) offers an add-on on how to optimize certain government policies.

\section{Conclusion}

In Asia there are some key competing regions with different national characteristics, such as Japanese regionalism, Korean regionalism, and Chinese regionalism. However, it is clear that the prospects of prosperity and a brighter economic future far outweigh the challenges. After all, Asians do need to develop their own policies, heeding their very own challenges. The primary task for countries in Asia's regional cooperation is to integrate these obviously contradictory and competing regionalisms into a relatively single and shared regional union.

The Asian Economic Union is a goal to work for.

\section{References}

[Online] Available: http://en.wikipedia.org/wiki/Timeline_of_European_Union_history (Feb. 11, 2009)

[Online] Available: http://www.gl88.net/webpages/asean.htm 
[Online] Available: http://www.zfzq.com/zfzq/content/html/20030110/content002001003_1000577223.html (translated from Chinese to English) (Nov. 26, 2008)

Adler, Ilya. (2001). Culture Shock. Business Mexic, 21

Asia Development Bank. (2008). Strategy 2020, Asian Development Bank. [Online] Available: http://www.adb.org/documents/Policies/Strategy2020/Strategy2020-print.pdf (Feb. 11, 2009)

$\mathrm{Gu}$, Hongming. The Religion of Good -citizenship. [Online] Available: http://www.gdhqzz.cn/yaoyehua/library/bd_dzsk/bibliomania/more/zgrdjs.htm (Dec. 9, 2008)

Nash, John. (1950). Equilibrium points in n-person games. Proceedings of the National Academy of Sciences, 36, 48-49. Nash, John. (1951). Non-Cooperative Games. The Annals of Mathematics, 54, 286-295. [Online] Available: http://en.wikipedia.org/wiki/John_Forbes_Nash (Feb. 11, 2009)

Pang, Zhongying. Regionalization, Regionality, and Regionalism: A Perspective on East Asian Regionalism. [Online] Available: http://www.iwep.org.cn/wep/200311/wep200311 content_en.htm (Nov. 26, 2008)

Wendt, Alexander. (1999). Social Theory of International Politics, Cambridge University Press. pp.229

Yu, Xintian, Emerging East Asian Identification: A Cultural Perspective, [Online] Available: http://www.siis.org.cn/english/journal/2003/yuxintian.htm (Nov. 20, 2008) 